\section{The management of acute severe head injury}

This abstract outlines certain important concepts in the approach to the resuscitation, intensive care, and anaesthetic management of the head-injured patient, based on pathophysiological principles.

\section{Pathophysiology'}

Immediate phase (minutes)

There is an acute increase in systemic arterial pressure (SAP), a smaller increase in intracranial pressure (ICP), apnoea, and an isoelectric EEG. ${ }^{2}$ The SAP increases because of hypothalamic discharge; ICP because autoregulation of cerebral blood flow (CBF) is exceeded, and because there is widespread intracranial vascular spasm. The latter in due to microvascular haemorrhage and reflex vessel responses to shearing forces.

After about a minute all these disturbances abate, perhaps in part due to mobilization of endogenous opioids. ${ }^{3}$

\section{Insermediate phase (minutes to hours)}

Two distinctive pathophysiological sequences may evolve and often coexist: (i) Diffuse axonal injury - caused by shear/stretch injury to nerve and vessels. This pattern is manifested in particular with acceleration/deceleration injury and there may be an associated intracranial haematoma from vascular haemorrhage. (ii) Discrete lesions: contusions and haematomas from direct cerebral trauma.

Secondary factors will impact upon the "primary brain injury":

Hypotension (systolic BP $<90$ ). Except in small children this is almost always due to extracranial injury and is devastating: the mortality rate is quadrupled. A normal cardiac output, not merely BP, is critical to adequate cerebral perfusion. ${ }^{4}$

ii Hypoxaemia $\left(\mathrm{PaO}_{2}<60 \mathrm{mmHg}\right)$. Significant pulmonary shunting, usually clinically inapparent, occurs in up to 66 per cent of severe head injuries; ${ }^{5}$ and hypoxaemia is associated with a doubling of mortality. ${ }^{6}$ The causes include an 80 per cent increase in systemic metabolic rate, altered integrity of the alveolar-capillary membrane, release of vasoactive fibrin split products, and platelet aggregation. Fifty per cent of victims have at least a subtle increase in
T.J. Coonan MD FRCPC

lung $\mathrm{H}_{2} \mathrm{O}^{7}$ If a patient has had an episode of either hypotension or hypoxaemia, there will be an 83 per cent incidence of subsequent intracranial hypertension. ${ }^{8}$

iii Intracranial Hypertension $(>20 \mathrm{mmHg}$ ) is associated with a doubling of mortality. Evidence exists that a very aggressive maintenance of ICP $<15 \mathrm{mmHg}$ can improve outcome.? Virtually all victims with an intracranial space occupying lesion develop increased ICP and 50-80 per cent of those with diffuse axonal injury have increased ICP. ${ }^{10}$ Early after injury an elevated ICP relates to intracranial haematoma, congestive brain swelling, or traumatic subarachnoid haemorrhage. Cerebral oedema at this stage is unusual. It is critical that haemotomas are evacuated early; if possible within four hours. ${ }^{\text {II }}$

\section{Lare phase (hours to days)}

i Cytotoxic oedema will develop in the area of damage. $^{12}$

ii Vasogenic oedema - usually becomes significant after 24 hours and has a major role in the ICP reaching its zenith two to three days after injury. The blood brain barrier (BBB) is dysfunctional and becomes freely permeable to electrolytes as well as proteins. The alteration in BBB integrity after head injury is widespread but vasogenic oedema around areas of temporal or frontal lobe contusion is a particular problem. Lethal brain herniation can occur at an ICP well below $20 \mathrm{mmHg}$ in the presence of temporal lobe contusion.

iii Post-traumatic epilepsy occurs in four per cent of closed head injuries ${ }^{13}$ and ten per cent of depressed skull fractures ${ }^{14}$. - The incidence is even higher with brain laceration.

iv Systemic arterial hypertension relates to hypothalamic dysfunction with altered sympathetic and parasympathetic control. Subendocardial and myocardial necrosis is common, CPK-mb fractions are elevated and a wide variety of ECG abnormalities and dysthythmias occur - some of which are highly malignant. ${ }^{15}$ The ECG abnormalities correlate with a poor prognosis ${ }^{16}$

Department of Anaesthesia, Dalhousie University, Halifax, Nova Scotia. 
and circulatory hyperactivity is very responsive to beta blockade. ${ }^{17}$

v Cerebral circulatory control is dysfunctional. The $\mathrm{CMRO}_{2}$ is low and this may be associated with either hyperaemia ( 55 per cent) or an appropriately low cerebral blood flow (45 per cent). ${ }^{18}$ Hyperaemia tends to be present in those subjects with congestive patterns on their CT scan (isodense, compressed ventricles and compressed subarachnoid cisterns) but this pattern may be associated with a low $\mathrm{CBF}$ and is not completely reliable. Hyperaemia is common in those patients who have had an hypotensive or hypoxic event and it is particularly common in children. ${ }^{19}$ Therapeutic hypocapnia is beneficial in the presence of hyperaemia but may be dangerous for patients with a low CBF. ${ }^{18}$ There are methods for determining $\mathrm{CMRO}_{2} / \mathrm{CBF}$ ratio ${ }^{20-22}$ but their applicability has not been established.

vi Disseminated intravascular coagulation related to high levels of brain thromboplastin has been described often (3-13 per cent) ${ }^{23}$ and other multisystem superimposed conditions have been reviewed. ${ }^{7}$

\section{Initial management and resuscitation ${ }^{24,25}$}

Mortality can be decreased 52 per cent with good emergency care. ${ }^{26}$ Emergency assessment has been reviewed ${ }^{24,25,27}$ and particular mention must be made of the oval pupil and the small reactive pupil as harbingers of temporal lobe herniation.

i Immediate airway control - This correlates well with survival. The patient should be intubated if: (a) there is doubtful adequacy of ventilation; (b) the Glasgow Coma Score (GCS) is seven or less; (c) painful stimulation cannot be localized.

During intubation coughing and surges of CBF should be avoided. It would seem reasonable to administer $1.5 \mathrm{mg} \cdot \mathrm{kg}^{-1}$ lidocaine 90 seconds prior to intubation plus as much thiopentone as the patient's haemodynamic status will allow: up to $3 \mathrm{mg} \cdot \mathrm{kg}^{-1}$. 28 No agent will prevent an increase in ICP if the patient coughs. Succinylcholine can excite the brain, increase $\mathrm{CMRO}_{2}$, and elevate $\mathrm{CBV}^{29}$. However, provided that the succinylcholine is preceded by a small "defasciculating" dose of a non-depolarizing relaxant and thiopentone is used, there will be no significant increase in ICP. ${ }^{30}$

An hyperkalaemic response to succinylcholine has been recorded following prolonged bed rest in at least three head injured patients. ${ }^{31}$ The applicability of this to the acute situation is doubtful. However, should one elect to avoid succinylcholine, vecuronium in large doses will provide good rapid intubating conditions.
In five to ten per cent of victims there will be a fractured cervical spine in addition to the head injury. The management of such patients is controversial and requires resolution of conflicting principles. Provided that no difficulty in intubation is expected, direct laryngoscopy and intubation, with the neck stabilized in traction, and using cerebral protection, may be the best course of action.

ii Fluid resuscitation should be with isotonic solutions. Ringer's lactate is relatively hypotonic (250-260 mosm $\left.\cdot \mathrm{kg}^{-1}\right) \cdot{ }^{32}$ Normal saline in large quantities may result in a hyperchloremic metabolic acidosis; therefore a combination of normal saline and Ringer's lactate might be preferable. Albumin is probably not critical for effective resuscitation. ${ }^{33}$

iii Blood gases should be carefully controlled. The $\mathrm{PaO}_{2}$ is aggressively maintained above $70 \mathrm{mmHg}$. A higher $\mathrm{PO}_{2}$ is advisable in the presence of cerebral oedema to enhance $\mathrm{O}_{2}$ diffusion. Moderate hypocapnia is usually employed at least initially to a level of $28-30$ $\mathrm{mmHg}$ in adults and $23-26 \mathrm{mmHg}$ in children. ${ }^{25}$

iv Head elevation of $15^{\circ}$ is usually used but this may decrease effective cerebral perfusion. ${ }^{34}$

$\checkmark$ Mannitol is not usually administered at this early stage in management because it may induce an acute increase in CBF if given quickly, In a crisis, with signs of major brainstem compression or tentorial herniation, mannitol is given in dosages of $0.5-1 \mathrm{~g} \cdot \mathrm{kg}^{-1}$ over ten minutes both in children and adults. ${ }^{25}$ Hypocapnia and perhaps thiopentone should precede the mannitol.

\section{Neurological intensive care}

All the principles outlined in "Resuscitation" apply. A few additional points will be outlined. The subject has been well reviewed previously, ${ }^{7,25,35}$

i Intracranial pressure monitoring is used, preferably with ventricular cannulae, in all patients with GCS of $\leq 7$. Some centres do not monitor ICP in patients with GCS 6 or 7 provided that: (a) the CT Scan is normal; (b) there has been no hypoxia, hypocapnia or hypotension; (c) there have been no other injuries.

ii The ICP is controlled at a level less than $20 \mathrm{mmHg}$. With frontal or temporal lobe lesions the ICP is maintained at less than $15 \mathrm{mmHg}$ by surgical decompression if necessary. ${ }^{35}$

iii Jugular venous pressure is minimized: (a) neck rotation or compression is avoided; (b) the mean intrathoracic pressure is minimized. Ventilation should be controlled so as to allow low respiratory rates with as much time in expiration as possible; (c) in those areas with disrupted BBB, intravascular pressure is the primary determinant of vasogenic oedema. Control of the central venous pressure (CVP) is important. 
Access for CVP monitoring is preferable with subclavian than internal jugular vein.

iv Sedation is important as stimulation can increase $\mathrm{CMRO}_{2}$ in comatose patients. Generally, narcotics (morphine $2-4 \mathrm{mg} \cdot \mathrm{hr}^{-1}$ ) and judicious dosages of benzodiazepines are used.

v Hypertension is controlled primarily with beta blockade followed by alpha blockade if necessary. Labetolol may be very useful. Direct vasodilators are avoided if possible. Unless there are signs of brain stem compression or tentorial herniation, systolic pressure is kept below $160 \mathrm{mmHg}$ - cerebral perfusion pressure is best kept above $70 \mathrm{mmHg}$.

vi Hyperthermia is aggressively treated and agents active at the hypothalamus will often be necessary. Chlorpromazine $2-5 \mathrm{mg}$ IV repeatedly may be particularly useful as an antipyretic, antihypertensive, and sedative.

vii In addition the Hct should be kept above 30, Serum $\mathrm{Na}^{+}$concentration should be kept less than 150 $\mathrm{mEq} \cdot \mathrm{L}^{-1}$ and the plasma osmolality should be kept between 285 and $315 \mathrm{mosm} \cdot \mathrm{kg}^{-1}$. Hyperglycaemia will increase the extent of cerebral damage and should be controlled.

If, despite routine management, there is an increase in ICP the following manoeuvres are used in sequence:

$i$ The CSF is drained for five minutes.

ii Mannitol is given $0.25-0.5 \mathrm{gm} \cdot \mathrm{kg}^{-1}$ over $5-15 \mathrm{~min}$ utes. Furosemide $0.15-0.3 \mathrm{mg} \cdot \mathrm{kg}^{-1} 15$ minutes after the mannitol will intensify and prolong its effect. ${ }^{35}$

iii Slightly increased ventilation is attempted.

iv Intensive barbiturate therapy is considered for patients with ICP $>25$ uncontrolled by conventional means. ${ }^{37}$

\section{The anaesthetic management}

Surgical stimulation will increase cerebral blood flow by the induction of hypertension and by direct cerebral arousal. An anaesthetic is therefore required although the patient is comatose.

\section{Intravenous agents}

i Thiopentone remains the most potent agent for reducing $\mathrm{CMRO}_{2}, \mathrm{CBF}$ and ICP. The decrease in $\mathrm{CMRO}_{2}$ is proportional to the decrease in CBF and the brain is not compromised. Systemic arterial pressure decreases but usually proportionately less than the ICP. As long as the patient is haemodynamically stable up to $15 \mathrm{mg} \cdot \mathrm{kg}^{-1}$ can be titrated without major cardiovascular disturbance or unduly prolonged effect. ${ }^{38}$ This must be done with caution and undue hypotension must be managed aggressively. ii Lidocaine decreases $\mathrm{CBF}$ and $\mathrm{CMRO}_{2}$ proportionately and can stabilize membranes in models of cerebral ischaemia. ${ }^{39}$

iii Midazolam depresses $\mathrm{CBF}$ and $\mathrm{CMRO}_{2}$ proportionately; its effect is less than that of thiopentone but it carries less cardiovascular depression.

iv Fentanyl in moderate dosages decreases $\mathrm{CMRO}_{2}$ and CBF proportionately but less than the previous agents. ${ }^{40}$ High doses of fentanyl are more problematic as very high doses can be associated with EEG arousal and frank convulsions. ${ }^{41}$

\section{Inhalational agents}

i Nitrous oxide in light planes of anaesthesia will stimulate the brain, increase $\mathrm{CMRO}_{2}$ and increase ICP. ${ }^{42}$ This does not seem to occur when $\mathrm{N}_{2} \mathrm{O}$ is used as an adjunct to significant levels of cerebral depressant drugs.

ii Isoflurane at normocapnia will increase CBV. The induction of hypocapnia in conjunction with the administration of isoflurane will prevent CBV from rising above normocapnic levels. However, when hypocapnia is used to manage intracranial hypertension, the administration of isoflurane will induce an increase in CBV above the hypocapnic levels. ${ }^{43}$ Whether this is prevented by the simultaneous administration of thiopentone is unclear.

From the start of surgical stimulation until the opening of the dura, it would seem reasonable to maintain moderate hyperventilation and provide analgesia with fentanyl $\left(8-10 \mu \mathrm{g} \cdot \mathrm{kg}^{-1}\right)$ along with sedation with thiopentone (up to $10-15 \mathrm{mg} \cdot \mathrm{kg}^{-1}$ ) in a carefully titrated manner. Lidocaine can also be used either as intermittent $1.5 \mathrm{mg} \cdot \mathrm{kg}^{-1}$ boluses or as an infusion of $12 \mu \mathrm{g} \cdot \mathrm{kg}^{-1} \cdot \mathrm{min}^{-1}$. 42 The surgeon should infiltrate the scalp with a local anaesthetic prior to incision. If this is inadequate to prevent the stress response, isoflurane or perhaps $\mathrm{N}_{2} \mathrm{O}$ may be added. Once the dura is opened isoflurane may be used freely as its effects on CBV can be observed. The use of $\mathrm{N}_{2} \mathrm{O}$ at this stage, since the level of anaesthesia is light, would seem to be unwise; an increase in $\mathrm{CMRO}_{2}$ is most undesirable.

Postoperatively ICP monitoring is important as the ICP will almost always be elevated. Acute cerebral hyperaemia and acute vasogenic oedema are common as is the recurrence of haematoma.

\section{References}

1 Miller JD. Head injury and brain ischaemia - implications for therapy. Br J Anaesth 1985; 57: 120-9.

2 Sullivan HG, Martinez J, Becker DP, Miller JD, Griffith 
$\boldsymbol{R}$, West $A O$. Fluid percussion model of mechanical brain injury in the cat. $J$ Neurosurg 1976; 45: 520-34

3 Hayes RL, Galinat BJ, Kulkarne P, Becker DP. Effects of naloxone on systemic and cerebral responses to experimental concussive brain injury in cats. J Neurosurg 1983; 58: 720-8.

4 Davis DH, Sundt TM. Relationship of cerebral blood flow to cardiac output, mean arterial pressure, blood volume, and alpha and beta blockade in cats. J Neurosurg 1980; 52: $745-54$.

5 Frost EAM, Arancibia CV, Shulman K. Pulmonary shunt as a prognostic indicator in head injury. J Neurosurg 1979; 50: 768-72.

6 Miller SD, Butterworth JF, Gudeman SK et al. Further experience in the management of severe head injury. $J$ Neurosurg 1981; 54: 289-99.

7 Matjasko $M J$. Multisystem sequelae of severe head injury In: Cottrell JE, Turndorf $\mathrm{H}$ (Eds.). Anesthesia and Neurosurgery. 2nd ed. St. Louis: The CV Mosby Co., 1986.

8 Jennett $S$. Pulmonary function in the head injured patient. In: Fitch W, Barker J (Eds.). Head Injury and the Anaesthetist. Amsterdam: Elsevier, 1985.

9 Saul TG, Ducker TB. Effect of intracranial pressure monitoring and aggressive treatment on mortality in severe head injury. J Neurosurg 1982; 56: 498-503.

10 Bruce DA, Schut L, Bruno LH, Wood JH, Sutten LN. Outcome following severe head injuries in children. $J$ Neurosurg 1978; 48: 679-88.

11 Seelig $J M$, Becker DP, Miller $J D$, Greenberg RP, Ward JD, Choi SC. Traumatic acute subdural hematoma. $N$ Eng J Med 1981; 304: 1511-8.

12 Overgaard J, Tweed WA. Cerebral circulation after head injury. J Neurosurg 1976; 45: 292-300.

13 Jennett $B$. Epilepsy after non-missile head injuries. Scot Med J 1973; 18: 8-13.

14 Jennett $B$, Miller $J D$, Braakman $R$. Epilepsy after nonmissile depressed skull fracture. J Neurosurg 1974; 41 : 208-16.

15 Rotem M, Constantini S, Shir $Y$, Cote S. Life-threatening torsade de pointes arrhythmia associated with head injury. Neurosurgery 1988; 23: 89-92.

16 VanderArk GD. Cardiovascular changes with acute subdural hematoma. Surg Neurol 1975; 3: 305-8.

17 Robertson CS, Clifton GL, Taylor AA, Grossman $R G$. Treatment of hypertension associated with head injury. J Neurosurg 1983; 59: 455-60.

18 Obrist WD, Langfitt TW, Jagge $J L, C r u z J$, Gennarelli $T A$. Cerebral blood flow and metabolism in comatose patients with acute head injury. Relationship to intracranial hypertension. J Neurosurg 1984; 61: 241-56.

19 Shapiro $K$. Special considerations for the pediatric age group. In: Cooper PR (Ed.). Head Injury. 2nd ed. Baltimore: Williams \& Wilkins, 1987, p. 367-89.

20 Frost $E A M$. Anesthesia for neurosurgical emergencies. Im: ASA Annual Refresher Course, Lecture 151, 1988.

21 Raphaely $R$. Central nervous system trauma in children. In: Rogers $\mathrm{M}$ (Ed.). Current practice in Anesthesiology. Toronto: BC Decker Inc., 1988, p. 268-72.

22 Saunders $F W$, Cledgett $R V T$. Intracranial blood velocity in head injury. A transcranial ultrasound doppler study. Surg Neurol 1988; 29: 401-9.

23 Crone $K R$, Lee $K S$, Kelly $O L$. Correlation of admission fibrin degradation products with outcome and respiratory failure in patients with severe head injury. Neurosurgery 1987; 21 : 532-6.

24 Eisenberg HM, Weiner RL, Tobaddor $K$. Emergency care: initial evaluation. In: Cooper PR (Ed.). 2nd ed. Baltimore: Williams \& Wilkins 1987, p. 20-33.

25 Bruce DA. Management of severe head injury. In: Cottrell JR, Turndorf H (Eds.). Anesthesia and Neurosurgery. 2nd ed. St. Louis: The CV Mosby Co., 1986, p. 150-72.

26 Klauber MR, Marshall LF, Toole BM, Knowllen, SL, Bavers $S A$. Cause of decline in head injury mortality rate in San Diego County, California. J Neurosurgery 1985 ; 62: 528-31.

27 American College of Surgeons' Committee on Trauma: Advanced Trauma Life Support Instructor Manual. Chicago: American College of Surgeons, 1981.

28 Hamill JF, Bedford RF, Weaver DC, Colohan HR. Lidocaine before endotracheal intubation: intravenous or laryngotracheal? Anesthesiology 1981; 55: 578-81.

29 Minton MD, Crosslight K, Stirt JA, Bedford RF. Increases in intracranial pressure from succinylcholine: prevention by prior nondepolarizing blockade. Anesthesiology 1986; 65: 165-9.

30 Stirt JA, Crosslight KR, Bedford RF, Vollmer D. "Defasciculation" with metocurine prevents succinylcholineinduced increases in intracranjal pressure. Anesthesiology 1987; 67: 50-3.

31 Stevenson $P H$, Birch AA. Succinylcholine-induced hyperkalemia in a patient with a closed head injury. Anesthesiology 1979; 51: 89-90.

32 Todd $M M$. Fluid and electrolyte therapy in neuroanaesthesia. World Congress Anesthesiologists' Refresher Course, Lecture 421, 1988.

33 Zornow $M H$, Scheller MS, Todd MM, Moore SS. Acute cerebral effects of isotonic crystalloid and colloid solutions following cryogenic brain injury in the rabbit. Anesthesiology 1988; 69: 180-4.

34 Rosner MJ, Coley IB. Cerebral perfusion pressure, intracranial pressure, and head elevation. $J$ Neurosurg 1986; 65: 636-41.

35 Marshall LF, Marshall SB. Medical management of 
intracranial pressure. In: Cooper PR (Ed.). 2nd ed.

Baltimore: Williams \& Wilkins, 1987.

36 Roberts PA, Pollay M, Engles C, Pendelton B, Reynoids E, Stevens $F A$. Effect on intracranial pressure of furosemide combined with varying doses and administration rates of mannitol. J Neurosurg 1987; 66: 440-6.

37 Eisenberg HM. Frankowski RF, Contant $C F$ et al. Highdose barbiturate control of elevated intracranial pressure in patients with severe head injury. J Neurosurg 1988; 69: 15-23.

38 Hunter AR. Thiopentone supplemented anaesthesia for neurosurgery. Br J Anaesth 1972; 44: 506-10.

39 Astrup J, Skovsted P, Gjerris F, Sorenson HR. Increase in intracellular potassium in the brain during circulatory arrest: effects of hypothermia, lidocaine, and thiopental. Anesthesiology 1981; 55: 256-62.

40 Messick JM, Newberg LA, Nugent M, Faust RJ. Principles of neuroanaesthesia for the nonneurosurgical patient with CNS pathology. Anesth Analg 1985; 64: 143-74.

41 Rao TLK, Nummaneni N. El-Etr AA. Convulsions: an unusual response to intravenous fentanyl administration. Anesth Analg 1982; 61: 1020-1.

42 Barker $J$. Anaesthesia and the head-injured patient. In: Fitch W, Barker J (Eds.). Head Injury and the Anaesthetist. Amsterdam: Elsevier, 1985.

43 Artu AA. New concepts concerning anaesthetic effects on intracranial dynamics. In: ASA Annual Refresher Course, Lecture 133, 1987. 